\title{
Radiological features in 82 patients with nevoid basal cell carcinoma (NBCC or Gorlin) syndrome
}

Virginia E. Kimonis, $M D^{1,2}$, Sarju G. Mehta, $M D^{2}$, John J. DiGiovanna, $M D^{3,5}$, Sherri J. Bale, PhD ${ }^{1}$, Behram Pastakia, $M D^{4}$

\begin{abstract}
Purpose: Nevoid Basal Cell Carcinoma Syndrome (NBCCS) is an autosomal-dominant disorder characterized by multiple basal cell carcinomas, jaw cysts, palmar/plantar pits, calcification of the falx cerebri, and spine and rib anomalies. NBCCS is due to mutations in PTCH1, the human homologue of the Drosophila segment polarity gene patched. Mutations are detected in approximately $60 \%$ to $85 \%$ of individuals tested by sequencing of PTCH1; therefore, clinical examination and x-rays remain important in diagnosis of NBCCS. Methods: We studied 82 NBCCS patients and 38 of their unaffected siblings at the NIH between 1985 and 1994. Chest, rib, spine, skull, hand and foot x-rays, brain MRI or CT, and pelvic ultrasound (in females) were obtained in the affected individuals and compared to their unaffected relatives. Results: The following features were significantly more frequent in those with NBCCS: calcification of the falx cerebri, the most frequent radiological feature, was present in $79 \%$ of patients $>20$ years and in $37 \%<20$ years, calcification of the tentorium cerebellum was present in $20 \%$, bridging of the sella in $68 \%$, and abnormal frontal sinus aeration in $18 \%$ of affected individuals. Bifid ribs most often involving the third, fourth, and fifth ribs were seen in $26 \%$; splayed, fused, and misshapen ribs in a further $16 \%$, and widened ends of clavicles in $12 \%$. Spine X-rays revealed calcification of the nuchal ligament in $18 \%$, fusion of vertebrae in $10 \%$, and hemivertebrae in $15 \%$. Flame-shaped lucencies of the metacarpals and/or phalanges were present in 30\%, modeling deformities of the phalanges in $14 \%$, and polydactyly of the feet in $4 \%$. The frequency of scoliosis, cervical ribs, absent or rudimentary ribs, spina bifida occulta, or short 4th metacarpal was not higher in the affected individuals as compared to their unaffected relatives. Except for falx calcification, the frequency of radiological manifestations was similar in different age groups. Cranial CT or MRI in 42 affected individuals revealed asymmetric or dilated ventricles in $24 \%$, cerebral atrophy in $10 \%$, cavum septum pellucidum in $19 \%$, dysgenesis or agenesis of the corpus callosum in $10 \%$, and meningioma in $5 \%$. Ovarian fibromas were detected in $17 \%$ of females. Conclusions: This study reports the varied radiological manifestations of NBCCS. In the absence of major features such as basal cell carcinomas, jaw cysts, or falx calcification, which is often not evident until the teen years, other radiological manifestations of the disorder can permit early diagnosis of NBCCS in childhood. This will allow optimum surveillance for medulloblastoma and other neoplasms (cardiac fibromas and basal cell carcinomas) associated with NBCCS. Genet Med 2004:6(6):495-502.
\end{abstract}

Key Words: Gorlin syndrome, nevoid basal cell carcinoma syndrome, PTCH1, radiological features

The NBCCS fully delineated by Gorlin and Goltz ${ }^{1}$ is an autosomal dominant disorder. The main features are multiple

\footnotetext{
From the ${ }^{1}$ Genetic Studies Section, Skin Biology Laboratory, NIAMS, NIH, Bethesda, Maryland; ${ }^{2}$ Division of Genetics, Childrens Hospital, Harvard Medical School, Boston, Massachusetts; ${ }^{3}$ Basic Research Lab, Center for Cancer Research, National Cancer Institute, NIH, Bethesda, Maryland; and the ${ }^{4}$ Department of Radiology, Clinical Center, NIH, Bethesda, Maryland; ${ }^{5}$ Dermatopharmacology Division, Department of Dermatology, Brown Medical School, Providence, Rhode Island. Present address for S.J.B. is GeneDx, Inc. 207 Perry Parkway, Gaithersburg, Maryland; Present address for B.P. is Veterans Affairs Hospital, Washington, $D C$.

Virginia E. Kimonis, MD, MRCP, Division of Clinical Genetics and Metabolism, Children's Hospital/Harvard Medical School, 300 Longwood Avenue, Fegan 10, Boston, MA 02115. Received: May 14, 2004.

Accepted: August 10, 2004.
}

DOI: 10.1097/01.GIM.0000145045.17711.1C basal cell carcinomas (BCCs), or one BCC $<20$ years, keratocysts of the jaw, palmar/plantar pits, calcification of the falx cerebri, and spine and rib anomalies. NBCCS is due to mutations in PTCH1, the human homologue of the Drosophila segment polarity gene patched. ${ }^{2,3}$ Previous studies on the skeletal malformations in NBCCS include the following: Dunnick et al. ${ }^{4}$ reported the incidence of radiological features in 27 individuals with NBCCS evaluated at the National Institutes of Health before 1978. Four population-based studies, one each from the UK, ${ }^{5}$ Australia, ${ }^{6,7}$ USA, ${ }^{8}$ and Italy ${ }^{9}$ have reported the frequency of the clinical features in NBCCS patients. Kimonis et al. ${ }^{8}$ reported the important clinical features in 105 individuals with NBCCS in a large US cross-sectional study conducted at the National Institute of Health. Basal cell carcinomas, seen in $80 \%$ whites and $38 \%$ African-Americans, occurred at a 
mean age of 21 years. Palmar/plantar pits, the most prevalent clinical feature at all ages was seen in $87 \%$ individuals. Jaw cysts were reported or detected on dental evaluation in $74 \%$ of affected individuals at a mean age of 17 years. Skeletal features in these individuals reported by Kimonis et al. ${ }^{8}$ included pectus deformities in $12 \%$, Sprengel deformity in $11 \%$, and syndactyly in $24 \%$ of individuals. The aim of the present study was to delineate the radiological features in affected individuals with NBCCS. The unaffected siblings were included in the study in order to statistically analyze the clinical and radiological features that were prevalent predominantly among the affected individuals, thus overcoming bias. The results provide us with useful radiographic criteria in establishing a diagnosis in NBCCS.

\section{MATERIALS AND METHODS}

Patients were recruited at the National Institute of Health between 1985 and 1994. Criteria used for ascertainment of NBCCS for purposes of the study were the presence of 2 major, or 1 major and 2 minor criteria ${ }^{8}$ (Table 1 ). Twenty multiple-case families were recruited. There were 6 isolated cases representing likely de novo mutational events. Radiological studies were performed on 82 ( 35 males and 47 females) affected individuals who met criteria for NBCCS and 36 unaffected individuals. The age range of individuals at the time of examination was 4 months to 87 years (median 34.5 years). The 36 unaffected

Table 1

Diagnostic criteria used for NBCCS8

Criteria used for ascertainment of NBCCS for purposes of the study were the presence of 2 major or 1 major and 2 minor criteria

\section{Major criteria \\ More than 2 BCCs or one BCC under the age of 20 years \\ Odontogenic keratocysts of the jaw proven by histology \\ Three or more palmar or plantar pits \\ Lamellar calcification of the falx cerebri \\ Rib anomalies (bifid, synostosed, hypoplastic) \\ Ovarian fibroma \\ Medulloblastoma \\ Flame shaped lucencies of the phalanges \\ Brachymetacarpaly in all 4 limbs \\ First degree relative with NBCCS \\ Minor features \\ Any one of the following features: \\ Spina bifida occulta or other vertebral anomalies \\ Brachymetacarpaly in at least one limb \\ Hypertelorism or telcanthus \\ Frontal bossing}

A positive diagnosis was also established by the presence of a first degree relative with NBCCS and 1 major or 2 minor features. individuals ranged in age from 5.6 to 78 years. X-Rays evaluated included anteroposterior (AP) and lateral chest, rib, neck, and skull views in 82 individuals, spine films in 75 individuals, hand films in 80 individuals, and foot films in 52 individuals. Thirty-six affected individuals and two unaffected relatives had long bone and pelvic films. Forty-two affected and 2 unaffected individuals also had CT (37 individuals) or MRI (5 individuals) studies of the brain. All radiographs were evaluated by B.P.

Statistical analysis was performed using SPSS 6.1 for Windows. A Cross table analysis of the clinical features in the affected and unaffected groups was performed. Statistical significance using the Pearson test was demonstrated when a value of $P<0.05$ was obtained.

\section{RESULTS}

\section{Radiological features}

Skull films

Calcification of the falx cerebri was the most consistent radiological feature and was observed in $65 \%$ individuals with NBCCS (Fig. 1 and Table 2). The frequency of calcification of the falx varied with the age of the individual: 10/27 (37\%) of individuals under the age of 20 years, 20/26 (77\%) between the ages of 20 and 40 years, and 23/29 (79\%) over the age of 40 years. Among the unaffected individuals, only 2/36 (5\%) were

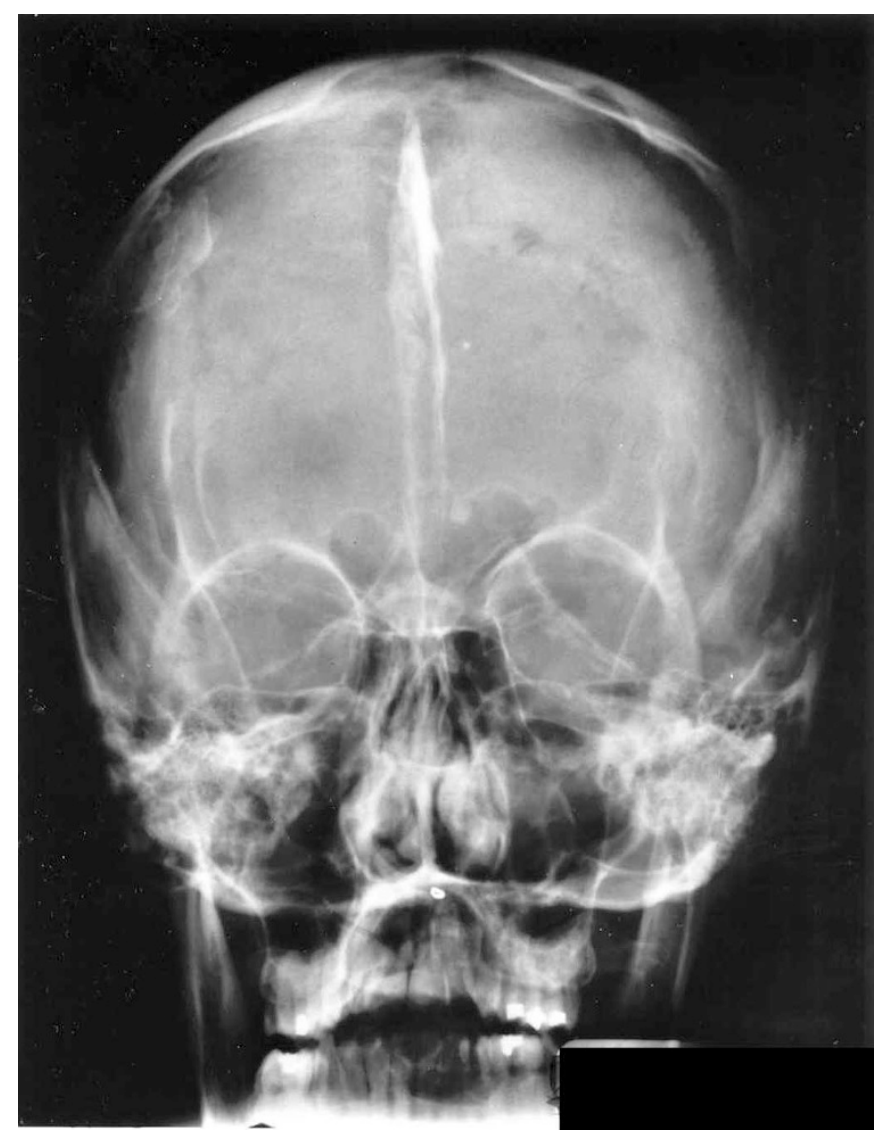

Fig. 1. Plain skull X-Ray of an individual indicating falx cerebri calcification. 
Table 2

Radiological features

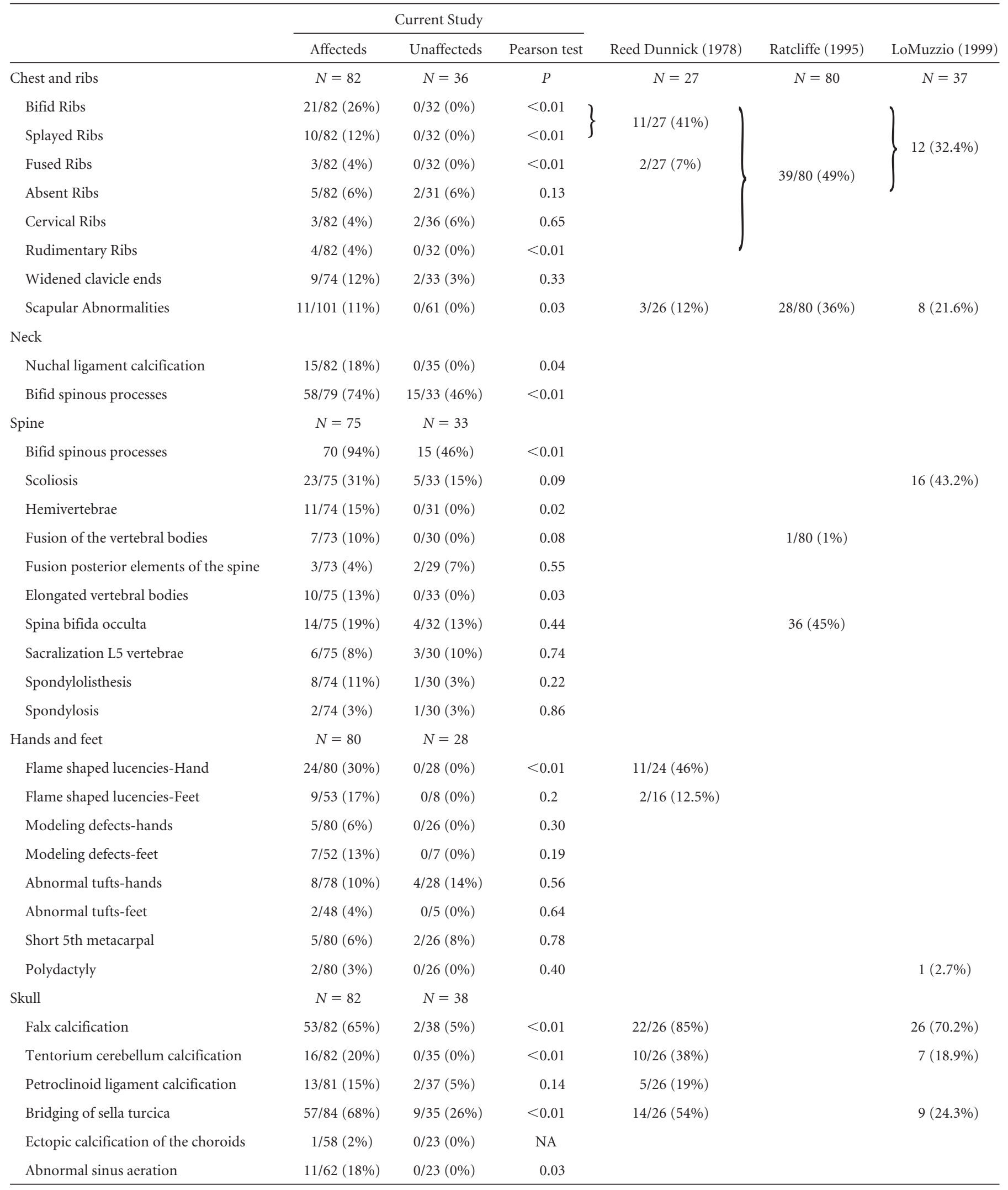


Table 2

Radiological features (continued)

\begin{tabular}{|c|c|c|c|c|c|c|}
\hline & \multicolumn{3}{|c|}{ Current Study } & \multirow[b]{2}{*}{ Reed Dunnick (1978) } & \multirow[b]{2}{*}{ Ratcliffe (1995) } & \multirow[b]{2}{*}{ LoMuzzio (1999) } \\
\hline & Affecteds & Unaffecteds & Pearson test & & & \\
\hline CT (37)/MRI (5) & $N=42$ & $N=2$ & & & & \\
\hline Asymmetric ventricles & $10 / 42(24 \%)$ & $0 / 2(0 \%)$ & & & & \\
\hline Cerebral Atrophy & $4 / 42(10 \%)$ & $0 / 2(0 \%)$ & & & & \\
\hline Cavum Septum Pellucidum & $8 / 42(19 \%)$ & $0 / 2(0 \%)$ & & & & \\
\hline Dysgenesis/agenesis corpus callosum & $4 / 42(10 \%)$ & $0 / 2(0 \%)$ & & & & \\
\hline Meningioma & $2 / 42(5 \%)$ & $0 / 2(0 \%)$ & & & & \\
\hline Ectopic calcification basal ganglia & $1 / 42(2 \%)$ & $0 / 2(0 \%)$ & & & & \\
\hline
\end{tabular}

observed to have mild calcification of the falx. These 2 individuals, age 50 and 75 years old, respectively, had no other features of NBCCS. Calcification of the tentorium cerebellum (20\%) was only observed in affected individuals. Calcification of the petroclinoid ligament seen as spur-like projections extending posteriorly and downwards from the dorsum was present in $15 \%$ of affected individuals and 2 unaffected (5\%) individuals. The petroclinoid ligament is formed by the margins of the tentorium as it extends from the petrous ridges of the temporal bones to the posterior clinoid processes of the dorsum sellae. Pituitary calcification was seen in one affected person. Hyperaeration of the frontal sinuses was observed in $18 \%$ of the NBCCS group only.

\section{CT/MRI of the cerebrum}

CT studies of the cerebrum were obtained in 42 and MRI studies in 5 persons with NBCCS. CT studies were later substituted for MRI studies because of the increased exposure to radiation with CT. The features observed were asymmetric ventricles in $10(24 \%)$ (in 5\% of cases this was related to previous surgery for medulloblastoma, and in the remaining attributed to communicating hydrocephalus), cerebral atrophy in $4(10 \%)$, cavum septum pellucidum in $8(19 \%)$, and dysgenesis/agenesis of the corpus callosum in $4(10 \%)$. Studies revealed meningioma in one individual who presented with symptoms of raised intracranial pressure and history revealed that he had previous radiation treatment for medulloblastoma. Multiple enhancing extraaxial masses consistent with the appearance of multiple meningiomas were observed in his MRI and CT (Fig. 2). No abnormal findings were noted in CT studies of the brain on 2 unaffected relatives.

\section{Chest and ribs}

Bifid ribs were observed in $26 \%$ affected individuals. The ribs that were most commonly affected were the third, fourth, and fifth ribs but first, second, seventh, and eighth rib anomalies were also noted. In several individuals, bifid or splayed ribs were associated with fusion and abnormal contour of the associated ribs (Fig. 3). Absent or rudimentary ribs were seen in 5 affected individuals (one had 11 pairs of ribs, two persons had unilateral or bilateral rudimentary 12th ribs, one had a rudimentary right seventh rib, and another a rudimentary 5 th rib). Other malformations of the ribs were also noted, such as splaying of the anterior ribs in a further $12 \%$. Abnormal widening of the anterior ends of the clavicles were seen in $12 \%$ of affected individuals. Two unaffected individuals were also noted to have absent ribs and widening of the anterior ends of the clavicles, respectively.

\section{Spine}

Lateral skull and neck films revealed calcification of the nuchal ligament or its attachment in $18 \%$ in the affected individuals. Bifid spinous processes of the cervical spine were seen at a higher frequency in the affected group (94\%), but also occurred in $46 \%$ of unaffected individuals.

Thoracolumbar spine films revealed scoliosis in $31 \%$ of affected versus $15 \%$ of unaffected individuals. Although this difference was not significant $(P=0.09)$, the scoliosis was noted to be more marked and primarily occurred at the site of an anomaly such as hemivertebrae, spina bifida occulta, or fusion of the vertebral bodies in the affected group. Anatomic abnormalities such as hemivertebrae (15\%) (Fig. 4), fusion of the vertebral bodies $(10 \%)$, or elongation of the vertebral bodies (13\%) were observed in affected individuals only.

Transitional vertebrae are often seen at the junction of the various divisions of the spine as a normal variant. No difference in the frequencies of sacralization of the spine and in the frequency of cervical ribs was found in the affected and unaffected groups. Similarly spondylolisthesis and spondylolysis of the spine was not increased in the NBCCS group. Fusion of the posterior elements of the spine was seen at the same frequency in both groups. In the affected group, missing posterior spinous processes especially of the cervical and upper thoracic spine were noted in 2 individuals. Two affected individuals also had a poorly formed sacrum.

\section{Long bones and pelvis}

A total of 36 affected and 2 unaffected individuals had radiographs of the pelvis and long bones. Cysts occurred in the femur, fibula, humerus in $2(6 \%)$, and in the ischium or radius 


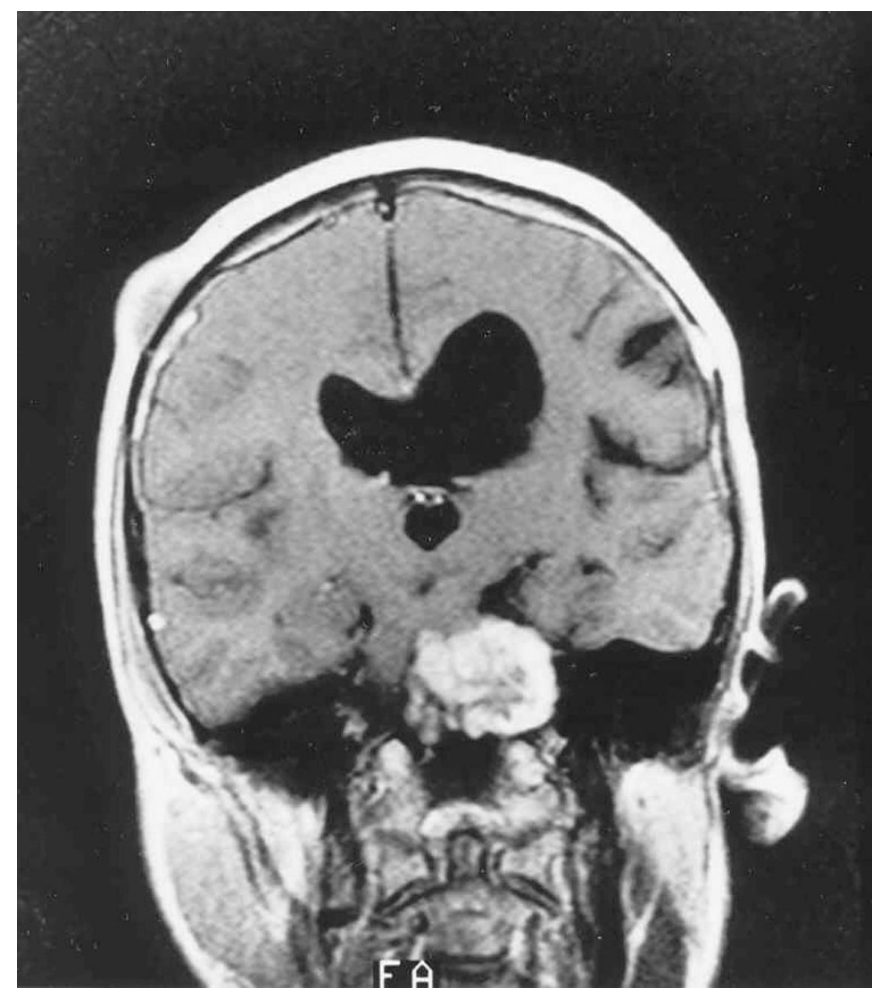

Fig. 2. Magnetic resonance imaging of the brain from a male age 25 years shows a large meningioma in the left cerebellopontine angle measuring $3 \times 6 \mathrm{~cm}$ causing mass effect upon the adjacent brain stem and left middle cerebellar peduncle with deformity of the fourth ventricle. Additional $1.5 \mathrm{~cm}$ diameter enhancing extraaxial masses were also present in both middle cranial fossae anteriorly. The patient underwent resection of left trigeminal schwannoma and left frontotemporal meningioma, the etiology of which was considered to be prior radiation therapy. He had a medulloblastoma at age 2 years, which was treated with resection, followed by radiation and cobalt treatment. He developed subsequent hydrocephalus, right exotropia with vision loss, and development delay. $\mathrm{He}$ developed an osteochondroma of the left $3 \mathrm{rd}$ rib at age 12 years, which required resection. BCCs developed at age 13 years in the distribution of the radiation treatment. He has a few palmar pits but no jaw cysts. He has a lumbar meningocele associated with marked lumbar lordosis, neurogenic bowel, and bladder. MRI of the lumbosacral spine revealed a lipoma in the posterior aspect of the sacral canal from S1-S4 and bony defects of the posterior elements of the sacral vertebrae.

in $1(3 \%)$ of persons with NBCCS. Increased trabeculation was noted in 3 femora, 2 tibiae $(8 \%)$, and 1 radius. Bone-in-bone changes were seen in $11 / 36(31 \%)$ individuals. Sclerotic changes were noted in 10 long bones from affected individuals. No anomalies were seen in the unaffected individuals.

\section{Hands and feet}

Flame-shaped lucencies as defined by Dunnick et al. ${ }^{4}$ were found more commonly in hand films than in foot films of affected persons (Fig. 5). Flame-shaped lucencies of the hand were observed in $30 \%$ and of the feet in $17 \%$ of radiographs studied in affected individuals and were not seen in the unaffected individuals. The youngest individual in whom lucencies were observed was a 6-year-old African American male who had previously been diagnosed with a medulloblastoma. His mother had prominent flame-shaped lucencies of her metacarpal, phalanges, distal radii, and ulna. No flame-shaped lucencies were observed in the unaffected group. Modeling defects

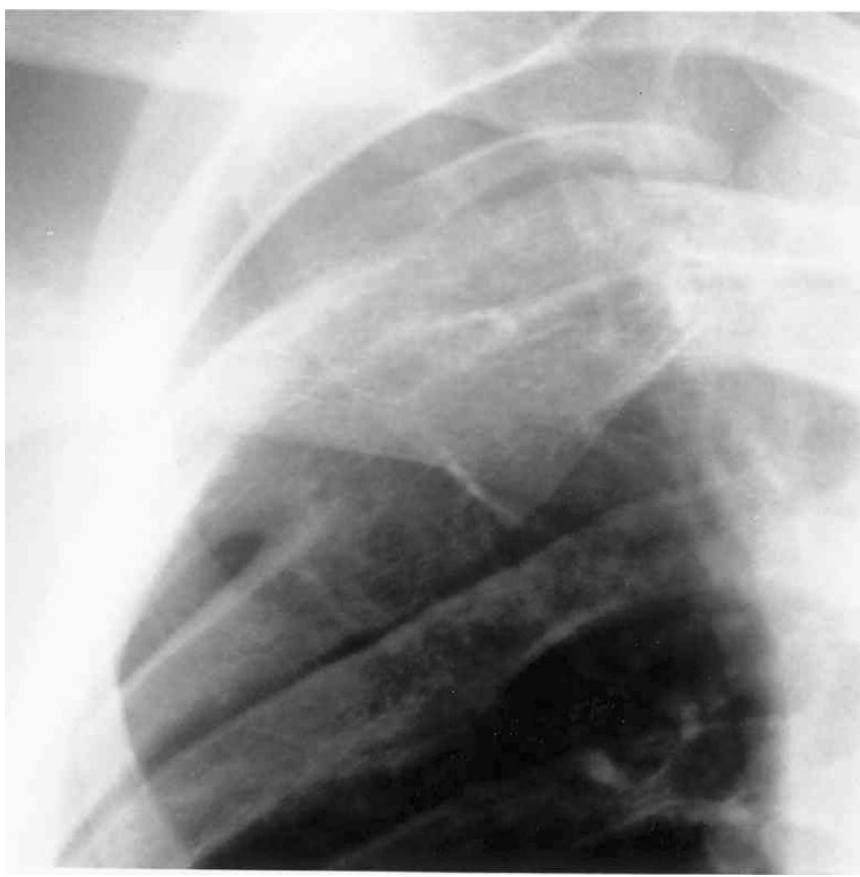

Fig. 3. X-Ray of ribs showing bifid, splayed and fused ribs.

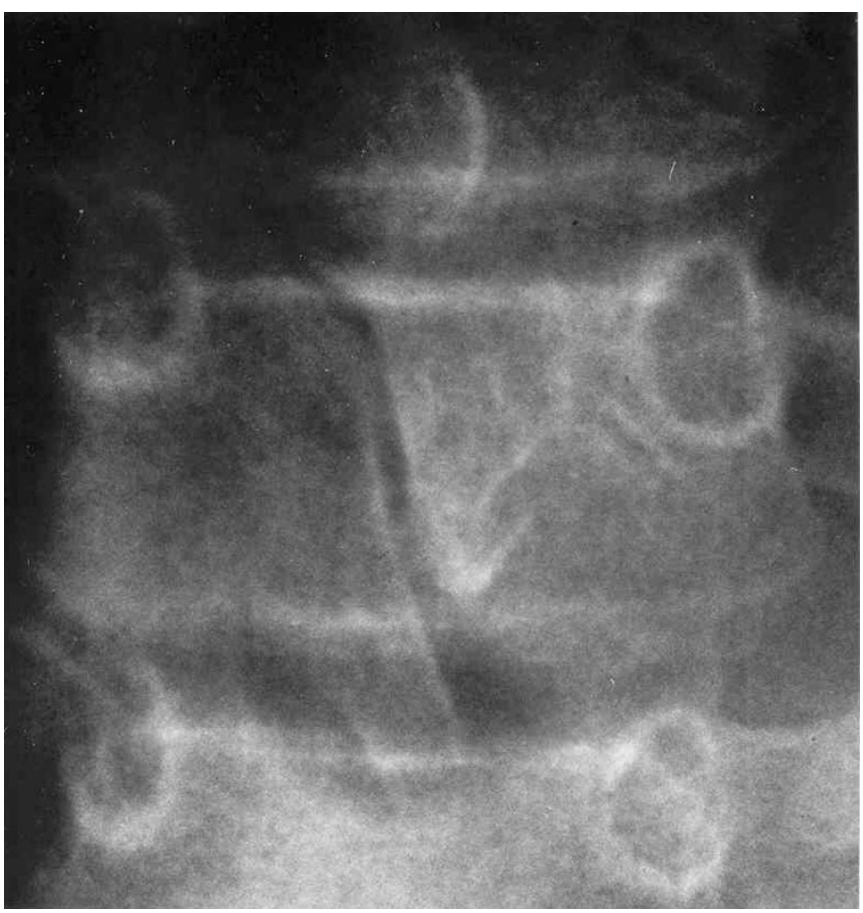

Fig. 4. $\mathrm{X}$-Ray of the thoracic vertebral spine revealing hemivertebrae.

of bones of the hands were noted in 5/80 (6\%) and of the feet in $7 / 52(13 \%)$ of the affected group. The modeling defects in the 12 affected individuals composed of abnormal contour of the phalanges, carpal, and tarsal bone. Polydactyly was present in 2 individuals. One 3-year-old male had partial polydactyly of the 5th metatarsal of the left foot (Fig. 6) and another individual had previous surgery for bilateral postaxial polydactyly of the 


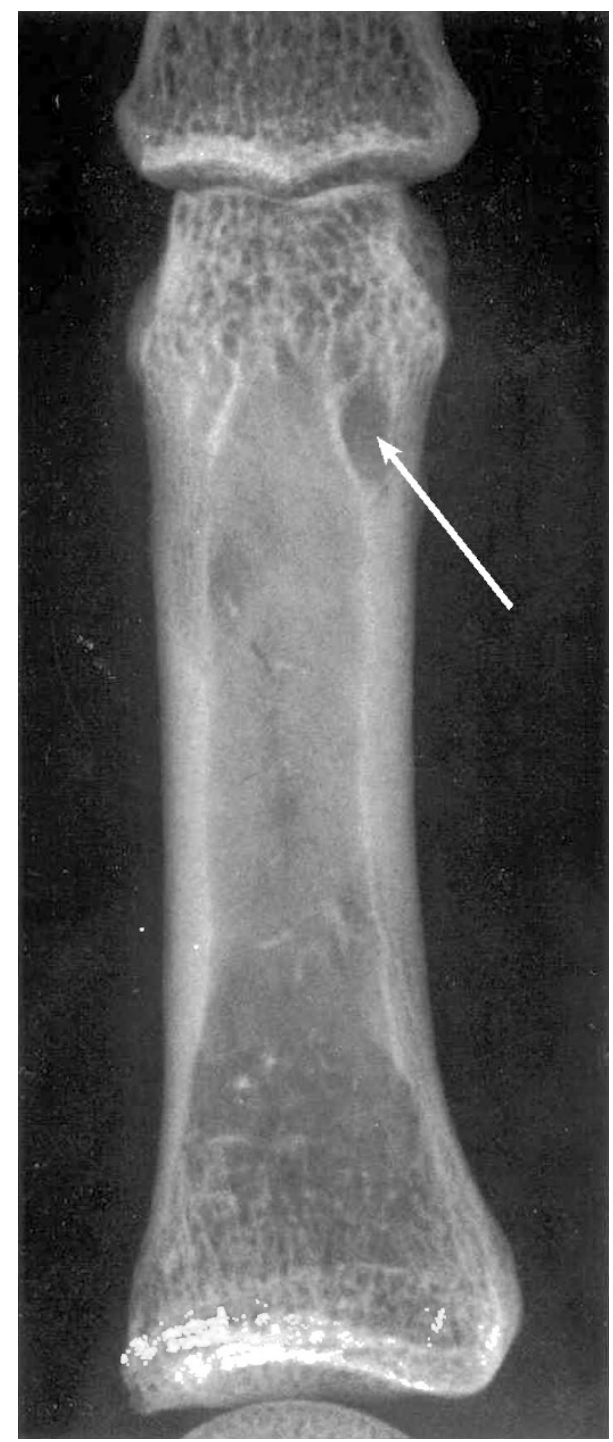

Fig. 5. Flame-shaped lucencies seen in a phalanx of the hand.

feet. Borderline shortening of the 4 th metacarpal was noted in $37 \%$ affected and in $30 \%$ of their unaffected relatives. Significant shortening of the 4 th metacarpal, however, was noted in $6 \%$ affected and in no unaffected individual. Short 5 th metacarpal was noted in $6 \%$ affected versus $8 \%$ unaffected individuals. These findings were not statistically different in the two groups.

\section{Pelvic ultrasound}

Seventeen percent (9/52) of females were found to have ovarian fibromas on routine screening. Their ages ranged from 16 to 45 years (mean 30.6 years). No fibroma was detected in 37 unaffected women.

\section{Unusual radiological features}

One individual had anomalous development of the craniovertebral junction and partial basilar assimilation. One 43year-old asymptomatic male fulfilling criteria of NBCCS had

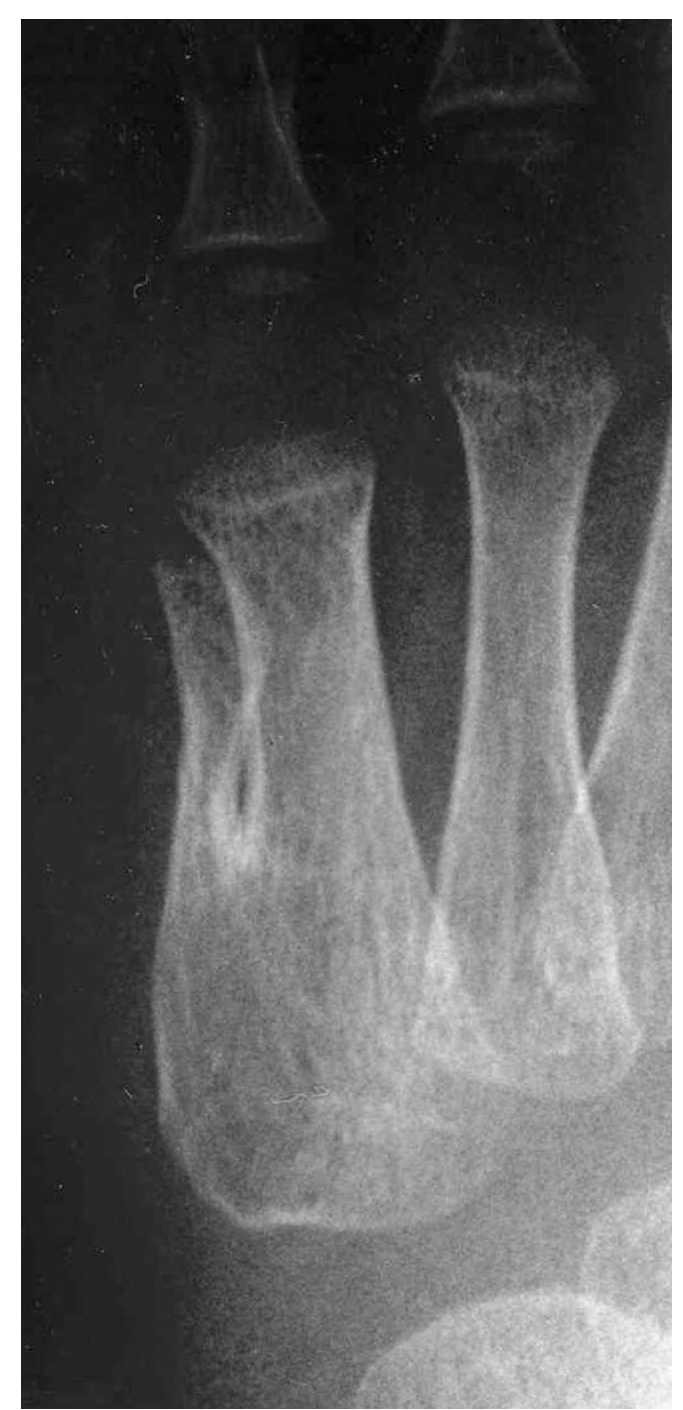

Fig. 6. Partial postaxial polydactyly of the 6th metatarsal of the foot.

bilateral adrenal calcification in normal sized adrenal glands. He had a previous history of pancreatitis at the age of 20 years.

\section{DISCUSSION}

The identification of a pathogenic mutation confirms a clinical diagnosis of NBCCS syndrome; however, not all patients who present with clinical features of NBCCS will have detectable PTCH1 mutations, likely due to current limitations in the methods used for mutation screening or implication of other genes. Using bidirectional dideoxy fingerprinting, Bale et al. ${ }^{10}$ reported mutations in 37 individuals from 10/15 (66\%) families recruited at the NIH. They reported genotype/phenotype variations, for example, persons with earlier onset of BCCs were more likely to have mutations toward the $5^{\prime}$ end of the gene and protein truncation mutations were associated with anomalies of the rib and spine. Other studies include that of Wicking et al. ${ }^{11}$ who screened for mutations by SSCP and heteroduplex analysis and reported mutations in 32 of 70 NBCCS 
cases (46\%) analyzed, $84 \%$ of which were protein-truncating mutations. Boutet et al. ${ }^{12}$ screened for PTCH1 mutations by SSCP and heteroduplex analysis in 65 French NBCCS families or sporadic cases and found 19 novel mutations (29\%) and five new polymorphisms in this group of patients, indicating that missense mutations make interpretation difficult in an individual with no family history of NBCCS who fails to fulfill diagnostic criteria. The detection rate $\left(19 \%-46 \%^{11,13}\right)$ can be improved by direct sequencing. Fujii, ${ }^{14}$ using direct sequencing analysis found mutations in PTCH1 in 6/8 Japanese NBCCS patients, however, exhaustive searching did not identify mutations in 2 cases.

Linkage analysis can be helpful in families in whom a mutation is not identified, however, is difficult in small families or in isolated cases (which constitute $1 / 3$ of cases). It is therefore often necessary to rely on clinical and radiographic features to make a diagnosis. Correct diagnosis is necessary for genetic counseling, prenatal diagnosis, and development of a management and surveillance plan for the complications of NBCCS. In NBCCS, the major clinical features develop between the teens and twenties, and therefore, radiological features become extremely important in helping establish the diagnosis, especially in children and young adults. Calcification of the falx, often described as bilamellar, is variable and develops with increasing age. We found CT of the brain to be more sensitive at detecting falx calcification before the calcification being detected on plain $\mathrm{x}$-ray films. However, this procedure is not recommended due to the increased exposure to radiation. Two unaffected older individuals had mild calcification of the falx. This frequency of $5 \%$ is similar to the rate $(5 \%-7 \%)$ found in previous population-based radiological studies. ${ }^{15,16}$ Calcification of the petroclinoid ligament observed (15\%) in our study has been reported in approximately $12.5 \%$ of individuals with $\mathrm{NBCCS}^{17}$ and in 5/26 (19\%) by Dunnick et al. ${ }^{4}$ in previous studies. Calcification of the tentorium cerebellum observed in $22 \%$ on plain skull film was only seen in affected individuals who had falx calcification. Dunnick et al. ${ }^{4}$ reported slightly higher incidences of calcification of the tentorium cerebelli in $10 / 26(38 \%)$. Bridging of the sella has been reported in 14/26 $(54 \%)^{4}$ and as a feature of NBCCS ${ }^{18-21}$; however, it was not found to be a discriminating feature in this study.

In our study, $41 \%$ of persons had rib abnormalities especially of the third to fifth ribs. Dunnick et al. ${ }^{4}$ also reported $11 / 27$ (41\%) with flared or bifid ribs and 2/27 (7\%) with synostosis in the NBCCS population versus $0.6 \%$ in the general population. ${ }^{22}$

Important vertebral spine anomalies were hemivertebrae, block, and elongated vertebrae. Other studies have also shown incomplete segmentation of the vertebral column..$^{20,23-25}$ Vertebral abnormalities were reported in $60 \%$ to $75 \%$ in NBCCS 26 ; however, the author included spina bifida occulta of the cervical and lumbar region, a finding that was not observed at an increased frequency in the NBCCS group in our study. Although scoliosis was not observed more frequently in the affected group, when it did occur, it was more severe and was associated with anomalies such as fusion of the vertebral bod- ies and fusion of the posterior elements of the spine and hemivertebrae. Anomalous development of the craniovertebral junction and partial basilar assimilation observed in one affected individual was also observed previously. ${ }^{27}$

Ovarian fibromas were found in $17 \%$ of females on routine screening similar to previous reports of $14 \%$ to $24 \%$ of the females studied. ${ }^{5,6}$ Ovarian fibromas are usually an incidental finding on ultrasound examination or at Caesarian section. They may cause torsion of the ovary, but are not thought to affect fertility. We do not recommend routine ultrasound based on our experience because no malignancies were found; however, they should be considered if symptoms develop suggestive of torsion. If operative treatment is required, preservation of ovarian tissue is recommended. ${ }^{31}$

Hand films were helpful because of the likelihood of observing flame-shaped lucencies (30\%), a feature not observed in the unaffected group. Modeling defects of the hands were noted in 5/74 (7\%) and of the feet in 7/52 (14\%). The modeling defects in the 12 affected individuals comprised abnormal contour of the phalanges, carpal and tarsal bones, and in two individuals, postaxial polydactyly was observed. Short 4th metacarpal and short 5th metacarpal are very common in the general population ${ }^{28}$ and are not a useful discriminating feature of NBCCS.

Radiological evaluation has proved valuable in establishing the diagnosis of NBCCS in children, and young adults before

Table 3

Radiological evaluation

\begin{tabular}{|c|c|}
\hline $\begin{array}{l}\text { Suggested radiological evaluations } \\
\text { for diagnosis }\end{array}$ & Features to look for \\
\hline \multirow[t]{4}{*}{ Skull } & Calcification of the falx cerebri \\
\hline & $\begin{array}{l}\text { Calcification of the tentorium } \\
\text { cerebellum }\end{array}$ \\
\hline & $\begin{array}{l}\text { Calcification of the petroclinoid } \\
\text { ligament }\end{array}$ \\
\hline & Hyperaeration of the frontal sinuses \\
\hline \multirow[t]{4}{*}{ Chest } & Bifid ribs \\
\hline & $\begin{array}{l}\text { Splaying of the ribs } \pm \text { fusion/abnormal } \\
\text { contours }\end{array}$ \\
\hline & Extra/missing ribs \\
\hline & $\begin{array}{l}\text { Abnormal widening of the anterior } \\
\text { ends of the clavicles }\end{array}$ \\
\hline \multirow[t]{3}{*}{ Spine } & $\begin{array}{l}\text { Calcification of the nuchal ligament/ } \\
\text { attachment }\end{array}$ \\
\hline & Marked scoliosis \\
\hline & $\begin{array}{l}\text { Hemivertebrae, fusion, or elongation of } \\
\text { the vertebral bodies }\end{array}$ \\
\hline \multirow[t]{3}{*}{ Hands and feet } & Flame shaped lucencies \\
\hline & Modeling defects \\
\hline & Shortening of the 4 th metacarpal \\
\hline Pelvic Ultrasound in females & Ovarian fibroma \\
\hline
\end{tabular}


the onset of jaw cysts and BCCs, and in African Americans who have a lower incidence of BCCs. ${ }^{29}$ The most useful radiographs are skull, chest and ribs, spine, hand and feet films, and ultrasound of the pelvis in females (Table 3). Jaw cysts are a common feature; therefore, mandible and panorex films should be obtained. Several individuals had some subtle manifestations of NBCCS such as vertebral anomalies or features such as mild falx calcification, or bridged sella but did not fulfill the clinical criteria. Mutation analysis may be helpful in identifying their status, which if negative does not rule out NBCCS, therefore careful follow-up is recommended.

Because of the limitations of mutations identification in the PTCH1 gene inpatients with clinical findings of NBCCS, clinical criteria and radiological examination still remains important to establish a diagnosis of NBCCS and provide appropriate surveillance. The current study analyzes statistical differences in frequency of features between affected and unaffected individuals. The diagnostic criteria used in making a diagnosis of NBCCS has therefore been revised from the original criteria used for ascertainment. ${ }^{8}$ As children often prove the greatest challenge in making the diagnosis of NBCCS, this information is important in identifying affected persons. ${ }^{30,31}$

\section{ACKNOWLEDGMENT}

We thank the families for their participation in this study, and Katerina Kimonis and Helen Chan for their assistance with the manuscript.

\section{References}

1. Gorlin RJ, Goltz RW. Multiple nevoid basal-cell epithelioma, jaw cysts and bifid rib: a syndrome. N Engl J Med 1960;262:908-912.

2. Hahn H, Wicking C, Zaphiropoulous PG, et al. Mutations of the human homolog of Drosophila patched in the nevoid basal cell carcinoma syndrome. Cell 1996;85:841851.

3. Johnson RL, Rothman AL, Xie J, et al. Human homolog of patched, a candidate gene for the basal cell nevus syndrome. Science 1996;272:1668-1671.

4. Dunnick NR, Head GL, Peck GL, Yoder FW. Nevoid basal cell carcinoma syndrome: radiographic manifestations including cystlike lesions of the phalanges. Radiology 1978;127:331-334.

5. Evans DG, Ladusans EJ, Rimmer S, Burnell LD, Thakker N, Farndon PA. Complications of the naevoid basal cell carcinoma syndrome: results of a population based study. J Med Genet 1993;30:460-464.

6. Shanley S, Ratcliffe J, Hockey A, et al. Nevoid basal cell carcinoma syndrome: review of 118 affected individuals. Am J Med Genet 1994;50:282-290.

7. Ratcliffe JF, Shanley S, Chenevix-Trench G. The prevalence of cervical and thoracic congenital skeletal abnormalities in basal cell naevus syndrome; a review of cervical and chest radiographs in 80 patients with BCNS. Br J Radiol 1995;68:596-569.
8. Kimonis VE, Goldstein AM, Pastakia B, et al. Clinical manifestations in 105 persons with nevoid basal cell carcinoma syndrome. Am J Med Genet 1997;69:299-308.

9. Lo Muzio L, Nocini PF, Savoia A, et al. Nevoid basal cell carcinoma syndrome. Clinical findings in 37 Italian affected individuals. Clin Genet 1999;55:34-40.

10. Bale SJ, Falk RT, Rogers GR. Patching together the genetics of Gorlin syndrome. J Cutan Med Surg 1998;3:31-34.

11. Wicking C, Shanley S, Smyth I, et al. Most germ-line mutations in the nevoid basal cell carcinoma syndrome lead to a premature termination of the PATCHED protein, and no genotype-phenotype correlations are evident. Am J Hum Genet 1997;60:2126.

12. Boutet N, Bignon YJ, Drouin-Garraud V, et al. Spectrum of PTCH1 mutations in French patients with Gorlin syndrome. J Invest Dermatol 2003;121:478-481.

13. Chidambaram A, Goldstein AM, Gailani MR, et al. Mutations in the human homologue of the Drosophila patched gene in Caucasian and African-American nevoid basal cell carcinoma syndrome patients. Cancer Res 1996;56:4599-4601.

14. Fujii K, Kohno Y, Sugita K, et al. Mutations in the human homologue of Drosophila patched in Japanese nevoid basal cell carcinoma syndrome patients. Hum Mutat 2003;21:451-452.

15. Nicotra A. La calcificazione e l'osteoma della falce del cervello, al controllo anatomo- radiologico e clinico. Arch Radiol (Napoli) 1929;5:794.

16. Bruyn GW. Calcification and ossification of the cerebral falx and superior longitudinal sinus. Psychiatr Neurol Neurochir 1963;66:98-119.

17. Stanton JB, Wilkinson M. Familial Calcification of petrosphenoidal ligament. Lancet 1949;2:736-767.

18. Anderson DE, Taylor WB, Falls HF, Davidson RT. The nevoid basal cell carcinoma syndrome. Am J Hum Genet 1967;19:12-22.

19. Gorlin RJ, Vickers RA, Kellen E, Williamson JJ. Multiple Basal-Cell Nevi Syndrome. An Analysis of a Syndrome Consisting of Multiple Nevoid Basal-Cell Carcinoma, Jaw Cysts, Skeletal Anomalies, Medulloblastoma, and Hyporesponsiveness to Parathormone. Cancer 1965;18:89-104.

20. McEvoy BF, Gatzek H. Multiple nevoid basal cell carcinoma syndrome:radiological manifestations. Br J Radiol 1969;42:24-28.

21. Mills J, Foulkes J. Gorlin's syndrome. A radiological and cytogenetic study of nine cases. Br J Radiol 1967;40:366-371.

22. Gross PP. Epithelioma adenoides cysticum with follicular cysts of maxilla and mandible. J Oral Surg Anesth Hosp Dent Serv 1953;11:160-165.

23. Eisenbud L, Brooks H, Busch S. Klippel-Feil syndrome with multiple cysts of the jawbones. J Oral Surg (Chic) 1952;5:659-666.

24. Pollard JJ, New PF. Hereditary Cutanemomandibular Polyoncosis. A Syndrome of Myriad Basal-Cell Nevi of the Skin, Mandibular Cysts, and Inconstant Skeletal Anomalies. Radiology 1964;82:840-849.

25. van Erp IF. Naevus epithelomatodes multiplex (" 5 th phacomatosis"-HermansGrosfeld-Valk). Dermatologica 1968;136:256-264.

26. Gorlin RJ, Sedano HO. Multiple nevoid basal cell carcinoma syndrome. In: Vinken PJ, Bruyn GW, ed. Handbook of clinical neurology. Amsterdam: North Holland Publishing Co.; 1972.

27. Pimenta WP PP, Brandao HJS. Sindrome de nevo-baso-cellular. Anais Bras Derm 1965;40:190-191.

28. Bloom RA. The metacarpal sign. Br J Radiol 1970;43:133-135.

29. Goldstein AM, Pastakia B, DiGiovanna JJ, et al. Clinical findings in two AfricanAmerican families with the nevoid basal cell carcinoma syndrome (NBCC). Am J Med Genet 1994;50:272-281.

30. Online database OMIM (Online Mendelian inheritance in man). Baltimore: Johns Hopkins University, Center for Medical Genetics, 1996. Available at: http:// www3.ncbi.nlm.nih.gov/omim/(May)

31. Genereviews, University of Washington, Seattle, 1993-2004. Available at: http:// www.geneclinics.org/servlet/access? db $=$ geneclinics\&site $=$ gt $\& i d=8888891 \& \mathrm{key}=$ TsdNaCSK5uhUT\&gry $=\& \mathrm{fcn}=\mathrm{y} \& \mathrm{fw}=7-\mathrm{OB} \&$ filename $=/$ profiles $/ \mathrm{bcns} / \mathrm{index} \cdot \mathrm{html}$ 